\title{
Efficacy of bronchoscopic lung volume reduction: a meta-analysis
}

\author{
This article was published in the following Dove Press journal: \\ International Journal of COPD \\ 14 May 2014 \\ Number of times this article has been viewed
}

\author{
Imran H Iftikhar' \\ Franklin R McGuire' \\ Ali I Musani² \\ 'Department of Medicine, Division \\ of Pulmonary, Critical Care and \\ Sleep Medicine, University of \\ South Carolina, Columbia, SC, USA; \\ ${ }^{2}$ Department of Medicine, Division of \\ Pulmonary, Critical Care and Sleep \\ Medicine, National Jewish Health, \\ Denver, CO, USA
}

Background: Over the last several years, the morbidity, mortality, and high costs associated with lung volume reduction (LVR) surgery has fuelled the development of different methods for bronchoscopic LVR (BLVR) in patients with emphysema. In this meta-analysis, we sought to study and compare the efficacy of most of these methods.

Methods: Eligible studies were retrieved from PubMed and Embase for the following BLVR methods: one-way valves, sealants (BioLVR), LVR coils, airway bypass stents, and bronchial thermal vapor ablation. Primary study outcomes included the mean change post-intervention in the lung function tests, the 6-minute walk distance, and the St George's Respiratory Questionnaire. Secondary outcomes included treatment-related complications.

Results: Except for the airway bypass stents, all other methods of BLVR showed efficacy in primary outcomes. However, in comparison, the BioLVR method showed the most significant findings and was the least associated with major treatment-related complications. For the BioLVR method, the mean change in forced expiratory volume (in first second) was $0.18 \mathrm{~L}$ ( $95 \%$ confidence interval [CI]: 0.09 to $0.26 ; P<0.001)$; in 6-minute walk distance was $23.98 \mathrm{~m}(95 \%$ CI: 12.08 to $35.88 ; P<0.01)$; and in St George's Respiratory Questionnaire was -8.88 points (95\% CI: -12.12 to $-5.64 ; P<0.001)$.

Conclusion: The preliminary findings of our meta-analysis signify the importance of most methods of BLVR. The magnitude of the effect on selected primary outcomes shows noninferiority, if not equivalence, when compared to what is known for surgical LVR.

Keyword: emphysema, endobronchial valves, sealants, stents, coils

\section{Introduction}

Chronic obstructive pulmonary disease (COPD) is now the third leading cause of death in the United States. ${ }^{1}$ In 2007, the economic burden of COPD in the US was $\$ 42.6$ billion in health care costs and lost productivity. ${ }^{2}$ Although different pharmacological treatments have shown improvement in lung functions in general COPD patients, the predominantly emphysema phenotypes with poor lung functions are often considered for additional surgical procedures. These include the bullectomy, ${ }^{3}$ single and double lung transplantation, ${ }^{4}$ and, more recently, lung volume reduction (LVR) surgery (LVRS). ${ }^{5}$ The latter is based on the concept that targeted resection of the damaged tissue that causes hyperinflation allows more space for the residual lung, which results in improvement of chest wall mechanics and transpulmonary recoil pressures. This and other factors appear to contribute to the physiological and symptomatic improvements that follow LVRS. The National Emphysema Treatment Trial (NETT) showed that the patients who benefited the most from LVRS in terms of survival and
Correspondence: Imran H Iftikhar

One Medical Park, Suite 300,

Columbia, SC 29203, USA

$\mathrm{Tel}+\mathrm{I} 8038733193$

Fax +I 803-454-2682

Email imran.iftikhar@uscmed.sc.edu submit your manuscript $\mid$ www.dovepress.com

Dovepress

http://dx.doi.org// 0.2147/COPD.S63378
International Journal of COPD 20I4:9 48I-49I (c) 92014 Iftikhar et al. This work is published by Dove Medical Press Limited, and licensed under Creative Commons Attribution - Non Commercial (unported, v3.0)
license. The full terms of the License are available at http://creativecommons.org/licenses/lby-nc/3.0/. Non-commercial uses of the work are permitted without any further permission from Dove Medical Press Limited, provided the work is properly attributed. Permissions beyond the scope of the License are administered by Dove Medical Press Limited. Information on how to request permission may be found at: http://www.dovepress.com/permissions.php 
functional improvement were those who had predominantly upper lobe emphysema and poor exercise capacity. ${ }^{5,6}$ However, significant short-term morbidity and mortality have been associated with LVRS. ${ }^{7}$ Furthermore, the associated costs of LVRS are almost prohibitive and make this a less attractive option for LVR. ${ }^{8}$

Different methods of bronchoscopic LVR (BLVR) have been studied, and more alternatives to LVRS are being studied in clinical trials. Most of the evidence in literature exists for one-way valves, sealants/hydrogels (from here on, collectively referred to as BioLVR), coil implants (LVR coils [LVRCs]), airway bypass stents, and bronchial thermal vapor ablation (BTVA) therapy. The valves work by preventing inspired air from entering target airways and allow exit of trapped air from distal airways. BioLVR therapy involves administration of a fibrinogen suspension and thrombin solution into the airways separately. Once in contact, these products polymerize into a hydrogel in situ. A localized inflammatory reaction ensues, causing atelectasis and remodeling, as well as a volume reduction over a 4- to 6-week period. BTVA uses heated water to produce thermal injury of the target tissue, which is followed by permanent fibrosis and atelectasis. Airway bypass stents have been used to create and maintain passages between the bronchi and emphysematous lobes. In the LVRC method, a coil is deployed into the target tissue. Once deployed, a coil conforms to its predetermined shape, by bending in the airway and causing compression of adjacent lung tissue, thereby creating local LVR. Since the advent of these new BLVR techniques, there has been no head-to-head comparison of one versus another. In this meta-analysis, we sought to analyze the comparative efficacy of each BLVR technique.

\section{Methods}

\section{Search strategy and selection criteria}

We searched PubMed and Embase databases from their inception to June 6, 2013. We used combinations of the following keywords: "endobronchial valves", "one way valves", "lung sealants", "coils", "lung volume reduction surgery", "bronchial thermal vapor ablation", and "emphysema". Boolean operators (AND/OR) were used to pair key search words. The search from PubMed yielded all the studies included in this meta-analysis. To ensure a thorough search of the literature, we handsearched the reference lists of the included studies and previously published meta-analyses. For inclusion in our meta-analysis, we considered only those studies that reported the pre- and post-LVR data on lung functions (in specific, the forced expiratory volume in 1 second $\left[\mathrm{FEV}_{1}\right]$, forced vital capacity [FVC], total lung capacity [TLC], residual volume [RV], and diffusion lung capacity of carbon monoxide [DLCO]), the 6-minute walk distance (6 MWD), and the St George's Respiratory Questionnaire (SGRQ). Prospective nonrandomized and randomized controlled trials (RCTs) were included, provided pre- and post-intervention data (absolute numbers) or mean difference (between pre- and post-intervention) were available. We included prospective nonrandomized consecutive case series but excluded case reports. Prospectively conducted multicenter cohort studies with retrospective analyses were also considered eligible for inclusion. However, retrospective cohort studies, as well as studies that reported data in median and interquartile range, were excluded. One investigator (IHI) independently searched the studies and performed the final screening. There were no disagreements between investigators on the inclusion or exclusion of a study. Figure 1 summarizes the results of the selection process. As a general rule, for multiple publications of the same trials, we intended to include only the most recent one. A total of seven studies ${ }^{9-15}$ from the subgroup of one-way valves, one from BioLVR, ${ }^{16}$ and two from BTVA ${ }^{17,18}$ were affected by this rule (see "Supplementary material" for details).

\section{Study outcomes}

Our primary outcomes included assessments of lung function (FEV 1 and FVC) measured in liters, lung volumes (TLC and RV) measured in liters, diffusion capacity (DLCO) measured in $\mathrm{mL} / \mathrm{min} / \mathrm{mmHg}$, assessment of exercise capacity (6 MWD) measured in meters, and assessment of the health-related quality of life with the SGRQ.

Analyses of secondary outcomes were related to the safety of a particular device or procedure. As the complications associated with each procedure were distinct from each other, we were not able to pool the data for a common outcome across different subgroups. For one-way valves, we included the incidence rates of pneumonia distal to valve, pneumothorax lasting more than 7 days, and migration of valves. For the BioLVR, we included the incidence rate of pneumonia and COPD exacerbations. For the LVRCs, we only included the incidence rate of COPD exacerbations. Data from the studies on airway bypass stents and BTVA were not sufficient enough to analyze.

\section{Data abstraction}

Data were extracted on a prespecified worksheet. This included first author's name, year of publication, number of study participants, their age and sex distribution, presence 


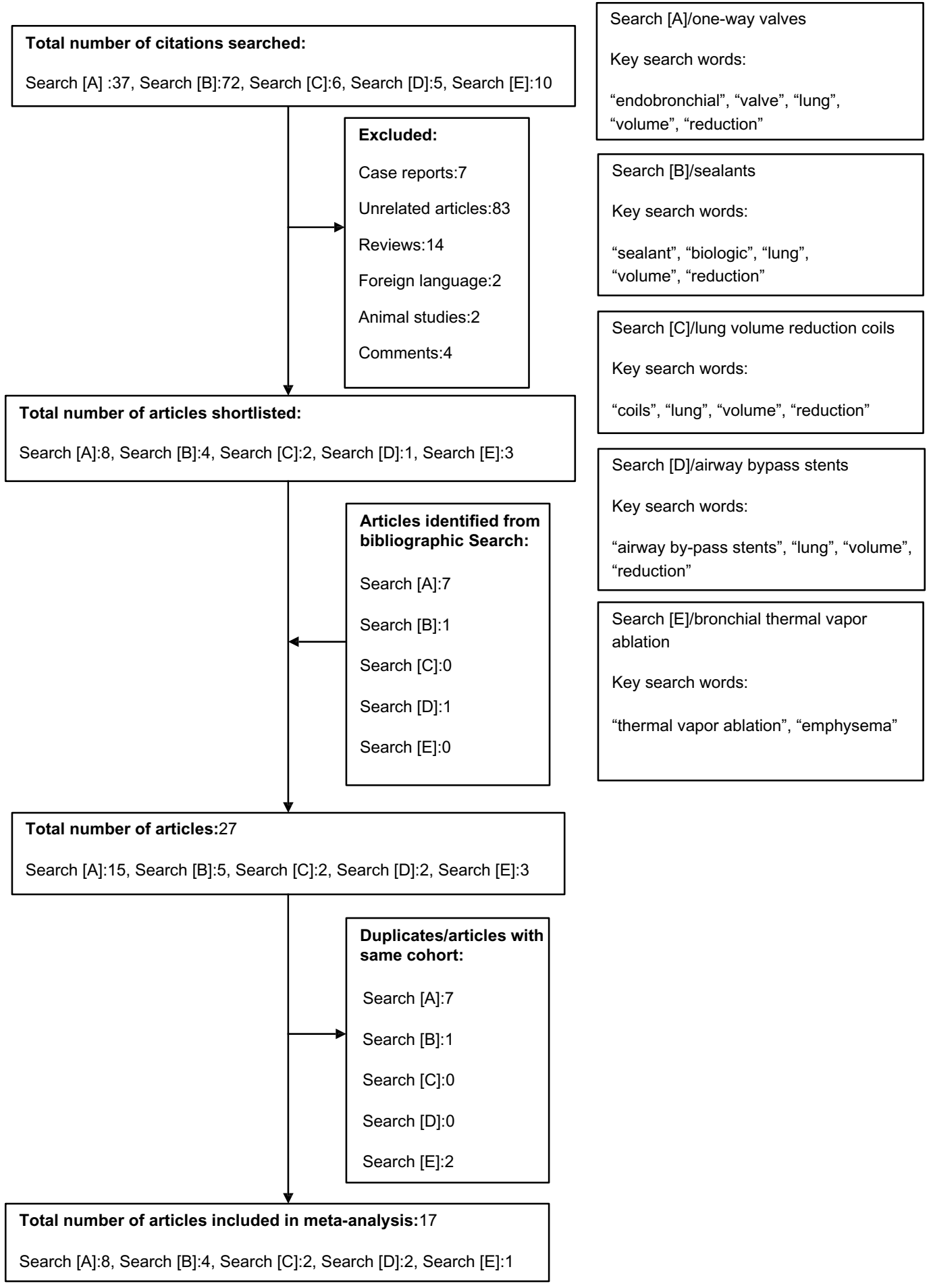

Figure I Flow diagram of articles identified and evaluated during the study selection process.

of comorbidities besides COPD, type of BLVR, country of origin, and study design. For the analysis, we recorded the mean of pre- and post-BLVR FEV 1 , DLCO, $6 \mathrm{MWD}$, and SGRQ with standard deviations (SDs), and, where necessary, the mean difference with SD or $95 \%$ confidence intervals (CIs). For any included study, where such information was not complete for a particular outcome of interest, this information was not included. In any included study, if outcomes were assessed at different time points, we obtained the data available for the longest follow-up. Where DLCO was available in $\mathrm{mmol} / \mathrm{min} / \mathrm{kPa}$ units, we used the conversion factor of 0.335 to obtain data in $\mathrm{mL} / \mathrm{min} / \mathrm{mmHg} .{ }^{19} 6 \mathrm{MWD}$ 
reported in feet was converted into meters using the following formula:

$$
1 \mathrm{ft}=0.3048 \mathrm{~m} \text {. }
$$

Standard errors (SES) were converted into SDs using the following formula:

$$
\mathrm{SD}=\mathrm{SE} \times(\sqrt{ } \mathrm{n})
$$

For RCTs, comparing a BLVR with either control or an active comparator, we extracted data only for the cohort that received BLVR (see "Supplementary material” for details).

\section{Quantitative data synthesis}

The mean changes in the outcomes from BLVR along with their $95 \%$ CIs were estimated by pooling the available data using Comprehensive Meta-Analysis software (v 2.2.064, Biostat, Englewood, NJ, USA). We separately analyzed the pooled changes in primary and secondary outcomes for each type of BLVR. Forest plots were constructed to analyze the results. Fixed effects methods were used to account for variance within the studies. Random effects methods were used to account for variance between and within the studies. ${ }^{20}$ Statistical heterogeneity was assessed with the $I^{2}$ statistic. ${ }^{21}$ An $I^{2}>60 \%$ indicated significant heterogeneity. Where moderate-to-high heterogeneity was noticed, we reported the results in random effects model. For our analysis of safety data, we used total number of events and person years to calculate the incidence rate for a particular safety outcome. Person years were calculated by multiplying the number of study participants at risk with the mean duration of follow-up (in years). If the number of cases was zero, a correction factor of 0.5 was added to both the events and person years. ${ }^{22}$ Data were pooled, and the results are displayed in the form of forest plots. To check for publication bias, we constructed funnel plots of effect size and standard error $^{20,23}$ and also analyzed results by using the Begg and Mazumdar rank correlation test. ${ }^{24}$

\section{Results}

\section{Study characteristics}

A total of 17 studies ${ }^{19,25-40}$ qualified for inclusion in the metaanalysis. The total number of study participants was 998 . There were eight studies for one-way valves, ${ }^{26,29,30,33-35,38,39}$ four for BioLVR, ${ }^{19,27,31,32}$ two for LVRC, ${ }^{28,37}$ two for airway

\begin{tabular}{|c|c|c|c|c|c|}
\hline Study, year & Study design & $\begin{array}{l}\text { Duration of } \\
\text { follow-up }\end{array}$ & $\begin{array}{l}\text { Number of participants } \\
\text { (\% of males) }\end{array}$ & $\begin{array}{l}\text { Age (years), } \\
\text { mean (SD) }\end{array}$ & $\begin{array}{l}\text { Type of } \\
\text { intervention }\end{array}$ \\
\hline Wan et al, ${ }^{39} 2006$ & Prospective multicenter registry & 90 days & $98(N / A)$ & $63(10)$ & One-way valve \\
\hline Sterman et al, ${ }^{38} 2010$ & $\begin{array}{l}\text { Multicenter prospective } \\
\text { cohort study }\end{array}$ & 12 months & $91(56)$ & $64.9(8.2)$ & One-way valve \\
\hline Sciurba et al, ${ }^{35} 2010$ & Multicenter RCT & 12 months $^{\mathrm{a}}$ & $220(60.4)^{b}$ & $65.34(6.83)^{\mathrm{b}}$ & One-way valve \\
\hline Chung et $a l,{ }^{26} 2010$ & $\begin{array}{l}\text { Prospective, single-center, } \\
\text { single-cohort }\end{array}$ & 90 days & $7(57)^{c}$ & $72(8)^{c}$ & One-way valve \\
\hline Santini et $\mathrm{al},{ }^{34} 20 \mathrm{II}$ & $\begin{array}{l}\text { Prospective, single-center, } \\
\text { single-cohort }\end{array}$ & 6 months & $9(100)$ & $57.77(21.48)$ & One-way valve \\
\hline Ninane et $\mathrm{al}^{33} 2012$ & Multicenter RCT & 3 months & $37(62)^{b}$ & $61(7)^{b}$ & One-way valve \\
\hline Herth et al, ${ }^{30} 2012$ & Multicenter RCT & 12 months & $111(68)^{b}$ & $59.7(7.9)^{\mathrm{b}}$ & One-way valve \\
\hline \multirow[t]{2}{*}{ Herth et al, ${ }^{29} 2013$} & Multicenter non-RCT & 30 days & CV-: $5 \mathrm{I}(5 \mathrm{I})$ & $C V-: 63(10)$ & One-way valve \\
\hline & & & $C V+: 29(45)$ & $C V+: 63(9)$ & \\
\hline \multirow[t]{2}{*}{ Criner et al, ${ }^{27} 2009$} & Open-label, multicenter, non-RCT & 6 months & LD hydrogel: 28 (67.9) & LD hydrogel: 65.1 (5.86) & BioLVR $^{d}$ \\
\hline & & & HD hydrogel: $22(50)$ & HD hydrogel: 66 (4.56) & \\
\hline Herth et al,,$^{19} 201 \mathrm{I}$ & Open-label, multicenter, non-RCT & 12 weeks & $25(68)$ & $62.7(7.4)$ & BioLVR \\
\hline Magnussen et al, ${ }^{32} 2012$ & $\begin{array}{l}\text { Retrospective analysis of datasets } \\
\text { from multicenter non-RCTs }\end{array}$ & 12 weeks & $54(69)$ & $62.9(7.2)$ & BioLVR \\
\hline Kramer et al, ${ }^{31} 2012$ & Multicenter open-label non-RCT & 12 months & $20(85)$ & $64(8)$ & BioLVR \\
\hline Herth et al, ${ }^{28} 2010$ & Pilot study - prospective cohort & 3 months & $11(27)$ & $62.5(4)$ & LVRC \\
\hline Slebos et al, ${ }^{37} 2012$ & Pilot study - prospective cohort & 6 months & $4(25)^{\prime}$ & $58(7.3)$ & LVRC \\
\hline Cardoso et al, ${ }^{25} 2007$ & Multicenter non-RCT & 6 months & $19(54.28)$ & 62 & $\begin{array}{l}\text { Airway bypass } \\
\text { stent }\end{array}$ \\
\hline Shah et $\mathrm{al}^{36}{ }^{36} 20 \mathrm{II}$ & Multicenter RCT & 12 months & $208(50)^{b}$ & $64.1(7.29)^{b}$ & $\begin{array}{l}\text { Airway bypass } \\
\text { stent }\end{array}$ \\
\hline Herth et al, ${ }^{40} 2012$ & $\begin{array}{l}\text { Two multicenter single-arm } \\
\text { prospective studies }\end{array}$ & 12 months & $44(50)$ & $63.1(5.6)$ & BTVA \\
\hline
\end{tabular}

Table I Baseline characteristics of studies

Notes: afficacy data obtained from 6 months follow-up in this meta-analysis; 'data represent participants in intervention cohort; 'only six completed the study; ${ }^{\mathrm{d} B i o L V R}$ indicates studies using sealants/hydrogels.

Abbreviations: BTVA, bronchial thermal vapor ablation; CV-, collateral ventilation absent; CV+, collateral ventilation present; HD, high dose; LD, low dose; LVR, lung volume reduction; LVRC, lung volume reduction coil; N/A, not applicable; RCT, randomized controlled trial; SD, standard deviation. 
bypass stents, ${ }^{25,36}$ and one for BTVA. ${ }^{40}$ Table 1 outlines the baseline characteristics of the study population. On average, study participants were $>58$ years old. The duration of follow-up lasted between 1 and 12 months. There were a total of four RCTs.

\section{Effect on primary outcomes}

For the studies using the BioLVR method, the pooled mean change in $\mathrm{FEV}_{1}$ was $0.18 \mathrm{~L}$ (95\% CI: 0.09 to $0.26 ; P<0.001$ (Figure 2), in 6 MWD was 23.98 m (95\% CI: 12.08 to 35.88 ; $P<0.01)$ (Figure 3$)$, and in SGRQ was -8.88 points $(95 \%$ CI: -12.12 to $-5.64 ; P<0.001$ ) (Figure 4 ).

The studies that used one-way valves showed a pooled mean change in $\mathrm{FEV}_{1}$ of $0.10 \mathrm{~L}$ (95\% CI: 0.00 to 0.19 ; $P=0.04$ ) (Figure 2), in $6 \mathrm{MWD}$ of $23.27 \mathrm{~m}$ (9.06 to 37.48; $P=0.001)$ (Figure 3$)$, and in SGRQ of -13.53 points $(-24.38$ to $-2.23 ; P=0.01$ ) (Figure 4 ).

Studies on BTVA showed a pooled mean change in $\mathrm{FEV}_{1}$ of $0.07 \mathrm{~L}$ (95\% CI: 0.02 to $\left.0.12 ; P<0.01\right)$ (Figure 2 ), in 6 MWD of $16.24 \mathrm{~m}(95 \% \mathrm{CI}:-1.92$ to $34.41 ; P=0.08)$ (Figure 3), and in SGRQ of -10.82 points (95\% CI: -14.95 to $-6.70 ; P<0.001$ ) (Figure 4 ).

Only 6 MWD and SGRQ data were analyzed for LVRC studies, which showed a pooled mean change of $84.4 \mathrm{~m}(95 \%$ CI: 48.43 to $120.36 ; P<0.001$ ) (Figure 3 ) and -10.79 points (95\% CI: -17.66 to $-3.92 ; P<0.01$ ) (Figure 4 ), respectively.

Table 2 and Figures S1-S4 summarize the results of all other primary outcomes, including FVC, TLC, RV, and DLCO.

\section{Effect on secondary outcomes}

The effects on secondary outcomes, defined a priori, are shown in Supplementary material. One-way valves were associated with an increased incidence of pneumonia distal to the valves (incidence rate of $0.05 ; P<0.001$ ), pneumotho$\operatorname{rax}>7$ days (incidence rate of $0.06 ; P<0.001$ ), and with valve migration (incidence rate of $0.01 ; P=0.03$ ). Results are shown in the form of forest plots in Figures S5-S7. BioLVR

Group by
intervention
BioLVR
BioLVR
BTVA
BTVA
BTVA
Stents
Stents
Stents
Valves
Valves
Valves
Valves
Valves
Valves
Valves
Valves
Valves

Study, year

n

\section{Difference in means and $95 \% \mathrm{Cl}$}

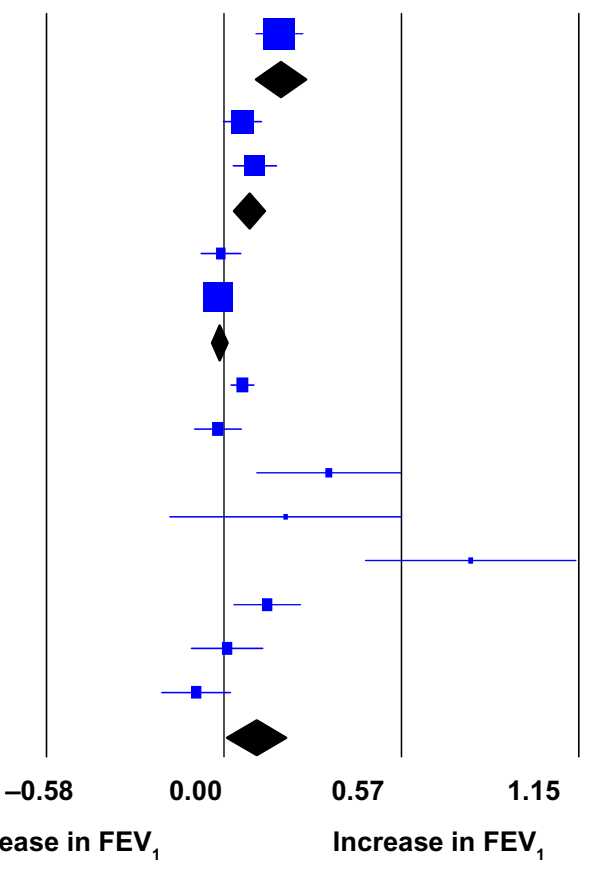

Figure 2 Change in $\mathrm{FEV}_{1}$.

Notes: The diamond reflects the $95 \% \mathrm{Cls}$ of the pooled estimate of mean difference. "BioLVR" indicates studies using sealants/hydrogels. "BTVA" indicates studies that used BTVA. "Stents" indicates studies using airway bypass stents. "Valves" indicates the subgroup of studies that used one-way valves. "GOLD" indicates stage of severity of chronic obstructive pulmonary disease.

Abbreviations: BTVA, bronchial thermal vapor ablation; $\mathrm{Cl}$, confidence interval; $\mathrm{CV}-$, collateral ventilation absent; $\mathrm{CV}+$, collateral ventilation present; $\mathrm{FEV}$, forced expiratory volume in the first second in liters; GOLD, Global initiative for chronic Obstructive Lung Disease; LVR, lung volume reduction. 


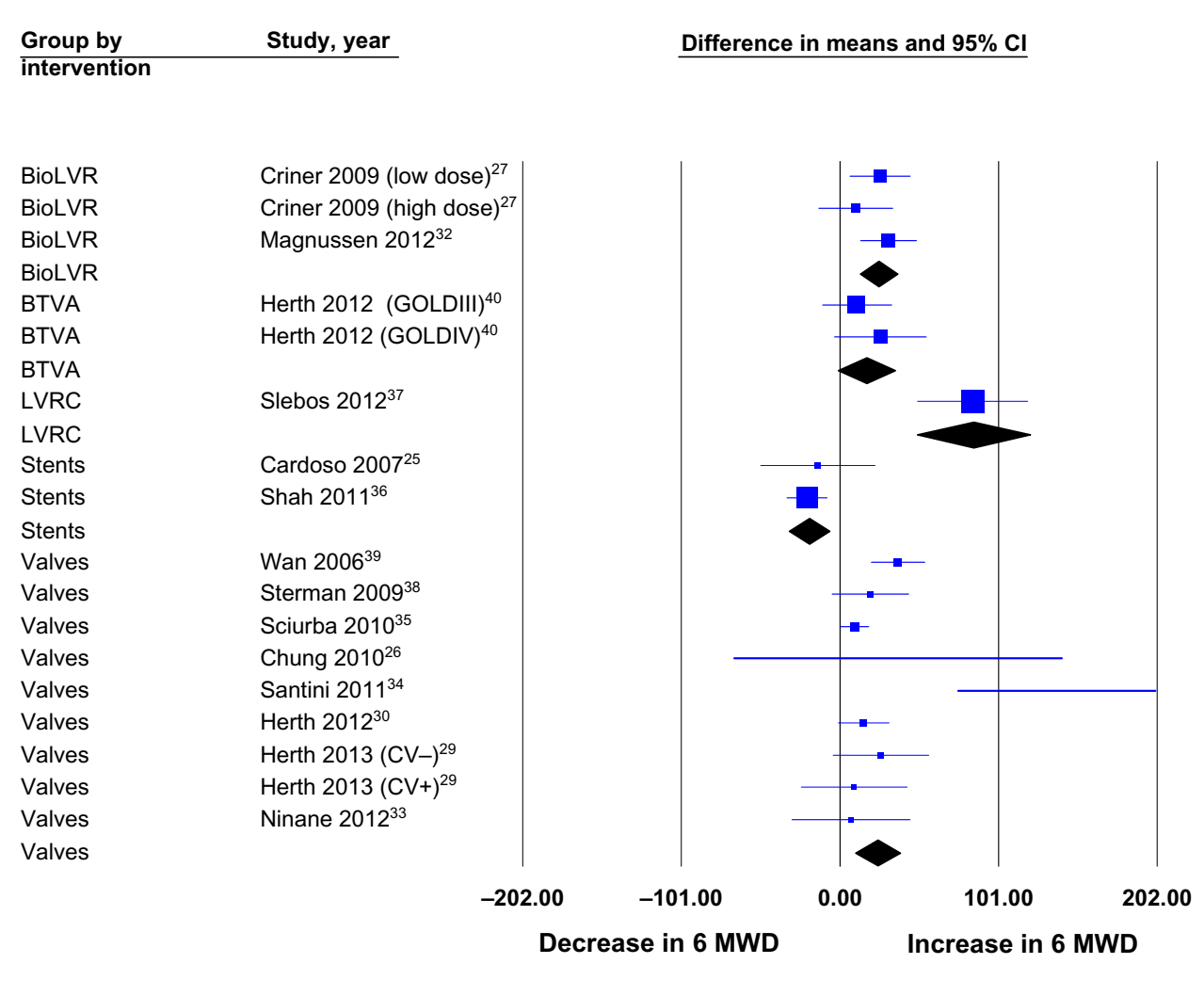

Figure 3 Change in 6 MWD.

Notes: The diamond reflects the $95 \% \mathrm{Cls}$ of the pooled estimate of mean difference. "BioLVR" indicates studies using sealants/hydrogels. "BTVA" indicates studies that used BTVA. "LVRC" indicates studies using LVRCs. "Stents" indicates studies using airway bypass stents. "Valves" indicates the subgroup of studies that used one-way valves. "GOLD" indicates stage of severity of chronic obstructive pulmonary disease. The 6 MWD test was measured in meters.

Abbreviations: 6 MWD, 6-minute walk distance; BTVA, bronchial thermal vapor ablation; Cl, confidence interval; CV-, collateral ventilation absent; CV+, collateral ventilation present; GOLD, Global initiative for chronic Obstructive Lung Disease; LVRCs, lung volume reduction coils.

and LVRCs had a unique association with treatment-related COPD exacerbations with an incidence rate of $0.07(P=0.04)$ and $1.30(P=0.01)$, respectively (Figures S8 and S9). BioLVR was also associated with an increase in treatment-related pneumonias (Figure S10).

\section{Assessment of publication bias}

The Begg and Mazumdar rank correlation tests ${ }^{24}$ did not show evidence of publication bias for the data on primary outcomes (see Tables S1 and S2).

\section{Post hoc analyses}

We separately analyzed studies from the subgroups of oneway valves, BioLVR, and LVRCs that studied participants for a minimum of 6 months. Results are reported in Table 3 and discussed below.

\section{Discussion}

To the best of our knowledge, this is the first meta-analysis that has systematically analyzed the effects of different forms of BLVR. Although our meta-analysis was designed to compare different methods used for BLVR, most of the studies included in our meta-analysis studied one-way valves. Consequently, this subgroup had the largest number of study participants compared to the other methods (BioLVR, LVRCs, airway bypass stents, and BTVA). Overall, the findings of our meta-analysis favor BioLVR as the most efficacious method of BLVR. This is because not only did this subgroup show a statistically significant difference in the assessment of lung functions $\left(\mathrm{FEV}_{1}, \mathrm{FVC}, \mathrm{TLC}, \mathrm{RV}\right.$, and DLCO), but also showed the most increase in exercise capacity (as assessed by the $6 \mathrm{MWD}$ ). Airway bypass stents seemed to lag behind in almost all of the primary outcomes. It also seemed paradoxical that this subgroup, in fact, showed a decrease in the $\mathrm{FEV}_{1}$. Direct comparison of the different BLVR methods for our secondary outcomes was not possible, since each method had a unique and different side effect profile. However, there did seem to be more procedure-/ device-related complications associated with the one-way valves than with the LVRCs or BioLVR. 


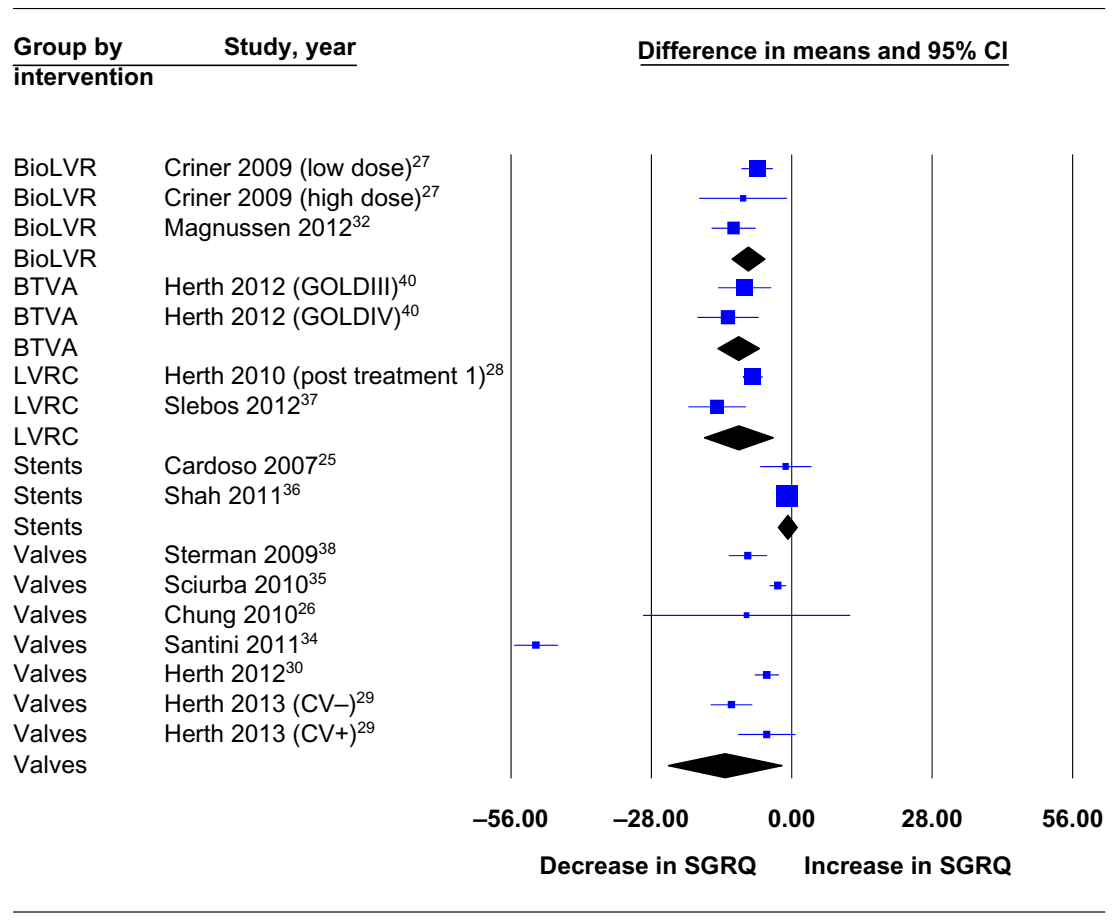

Figure 4 Change in SGRQ.

Notes: The diamond reflects the $95 \% \mathrm{Cls}$ of the pooled estimate of mean difference. "BioLVR" indicates studies using sealants/hydrogels. "BTVA" indicates studies that used BTVA. "LVRC" indicates studies using LVRCs. "Stents" indicates studies using airway bypass stents. "Valves" indicates the subgroup of studies that used one-way valves. "GOLD" indicates stage of severity of chronic obstructive pulmonary disease.

Abbreviations: BTVA, bronchial thermal vapor ablation; Cl, confidence interval; CV-, collateral ventilation absent; CV+, collateral ventilation present; GOLD, Global initiative for chronic Obstructive Lung Disease; LVRCs, lung volume reduction coils; SGRQ, St George's Respiratory Questionnaire.

Data from the NETT research group 5 indicate that, at 6 months post-LVRS, the change in $\mathrm{FEV}_{1}$ was $8.1 \% \pm 9.3 \%$ predicted at 6 months and $6.0 \% \pm 8.9 \%$ predicted at 12 months. This corresponds to an improvement of approximately $30 \%$ from baseline at 6 months and $22 \%$ from baseline at 12 months. The dominant finding of the NETT was an increase in the exercise capacity (defined as an increase in the maximal workload by more than 10 watts from baseline) and health-related quality of life, as measured by SGRQ, in those with predominantly upper lobe emphysema, in the surgical group versus the group that received medical therapy. ${ }^{5}$ The pre- to post-surgery data from the same study indicated that the change in $6 \mathrm{MWD}$ at 6 months and 12 months was $47.3 \pm 232.7 \mathrm{~m}$ and $14.4 \pm 275.1$ $\mathrm{m}$, respectively. ${ }^{5}$ This corresponds to an improvement of $3.88 \%$ and $1.18 \%$, respectively, compared to baseline. This study also showed that $68 \%$ of the 508 study participants randomized to surgery achieved an overall reduction in SGRQ scores. Most of the studies included in our meta-analysis had a shorter duration of follow-up and a much lower number of study participants compared to the NETT. However, results of our post hoc analysis correspond to an improvement in $\mathrm{FEV}_{1}$ of $43 \%$ and $31.2 \%$ in the subgroups of one-way valves and BioLVR, respectively. Similarly, for $6 \mathrm{MWD}$, results of our post hoc analysis correspond to an approximate $13.14 \%$ improvement in the subgroup of one-way valves and $5.34 \%$ in the subgroup of BioLVR. Thus, a comparison of our findings, in particular for $\mathrm{FEV}_{1}, 6 \mathrm{MWD}$, and SGRQ, with the data from NETT, at the same duration of follow-up (6-12 months), suggests noninferiority, if not equivalence, for BLVR. Indeed, the long-term follow-up data of 5 years from the NETT showed an overall survival advantage in the LVRS group compared to medical treatment. ${ }^{6}$ This data also showed significant improvements in exercise capacity and health-related quality of life (as measured by SGRQ) at 3 and 4 years post-surgery, respectively. While similar long-term data do not exist for most methods of BLVR, more recent data report that the 5-year survival rates in patients treated with one-way valves exceeded $80 \% .{ }^{12}$ However, in terms of the overall safety profile, if LVRS is associated with approximately $5.5 \%(5.5 \%$ in NETT and between $5 \%$ and $20 \%$ in others) 90 -day mortality, then, in comparison, current published literature shows that one-way valve therapy is associated with $1 \%$, airway bypass stents with $3 \%$, and BioLVR with $0 \%$ 90-day mortality. $15,25,27,41$

The mechanism of LVR differs between one-way valves, BioLVR, LVRCs, airway bypass stents, and BTVA. From a historical perspective, the methods have evolved. The first 
Table 2 Effect on primary outcomes

\begin{tabular}{|c|c|c|c|c|}
\hline Outcomes & Subgroup & $\mathbf{N}$ & Mean difference & Studies \\
\hline \multirow[t]{6}{*}{$\mathrm{FEV}_{1}$} & One-way valves & 500 & $0.10 \mathrm{~L}$ (95\% Cl: 0.00 to 0.19$), P=0.04$ & Wan et al, ${ }^{39}$ Sterman et al, ${ }^{38}$ Sciurba et al, ${ }^{35}$ \\
\hline & & & & Chung et al, ${ }^{26}$ Santini et $\mathrm{al},{ }^{34} \mathrm{Herth}$ et $\mathrm{al},{ }^{29}$ \\
\hline & & & & Ninane et $\mathrm{a}^{33}$ \\
\hline & BioLVR & 28 & $0.18 \mathrm{~L}(95 \% \mathrm{Cl}: 0.09$ to 0.26$), P \leq 0.00 \mathrm{I}$ & Magnussen et $\mathrm{a}^{32}$ \\
\hline & Airway bypass stents & 244 & $-0.01 \mathrm{~L}(95 \% \mathrm{Cl}:-0.04$ to 0.00$), P=0.14$ & Cardoso et al, ${ }^{25}$ Shah et al ${ }^{36}$ \\
\hline & BTVA & 44 & $0.07 \mathrm{~L}(95 \% \mathrm{Cl}: 0.02$ to 0.12$), P \leq 0.0 \mathrm{I}$ & Herth et $\mathrm{al}^{40}$ \\
\hline \multirow[t]{4}{*}{ FVC } & One-way valves & 107 & $0.42 \mathrm{~L}(95 \% \mathrm{Cl}:-0.24$ to $\mathrm{I} .06), P=0.2 \mathrm{I}$ & Wan et $\mathrm{al}^{39}$ Santini et $\mathrm{a}^{34}$ \\
\hline & BioLVR & 28 & $0.25 \mathrm{~L}$ (95\% Cl: 0.07 to 0.42$), P \leq 0.0 \mathrm{I}$ & Magnussen et a ${ }^{32}$ \\
\hline & Airway bypass stents & 244 & $0.03 \mathrm{~L}(95 \% \mathrm{Cl}:-0.24$ to $0.3 \mathrm{I}), P=0.79$ & Cardoso et al, ${ }^{25}$ Shah et al ${ }^{36}$ \\
\hline & BTVA & 37 & $0.24 \mathrm{~L}(95 \% \mathrm{Cl}: 0.10$ to 0.37$), P \leq 0.0 \mathrm{I}$ & Herth et $\mathrm{a}^{40}$ \\
\hline \multirow[t]{3}{*}{ TLC } & One-way valves & 95 & $-0.40 \mathrm{~L}(95 \% \mathrm{Cl}:-1.3 \mathrm{I}$ to 0.50$), P=0.38$ & Sterman et al, ${ }^{38}$ Santini et al, ${ }^{34}$ Ninane et $a^{33}$ \\
\hline & BioLVR & 28 & -0.73 L ( $95 \% \mathrm{Cl}:-1.43$ to -0.02$), P=0.04$ & Magnussen et $\mathrm{a}^{32}$ \\
\hline & Airway bypass stents & 36 & -0.1 I L (95\% Cl: -0.5 I to 0.29$), P=0.59$ & Cardoso et $\mathrm{a}^{25}$ \\
\hline \multirow[t]{5}{*}{ RV } & One-way valves & 193 & $-0.58 \mathrm{~L}(95 \% \mathrm{Cl}:-1.39$ to 0.22$), P=0.15$ & Wan et al, ${ }^{39}$ Sterman et al, ${ }^{38}$ Santini et al,,$^{34}$ \\
\hline & & & & Ninane et $\mathrm{a}^{33}$ \\
\hline & BioLVR & 28 & $-0.5 \mathrm{I}$ L $(95 \% \mathrm{Cl}:-0.8 \mathrm{I}$ to $-0.2 \mathrm{I}), P=0.00 \mathrm{I}$ & Magnussen et $\mathrm{a}^{32}$ \\
\hline & Airway bypass stents & 244 & $-0.24 \mathrm{~L}(95 \% \mathrm{Cl}:-0.65$ to 0.17$), P=0.25$ & Cardoso et al, ${ }^{25}$ Shah et al ${ }^{36}$ \\
\hline & BTVA & 37 & $-0.30 \mathrm{~L}(95 \% \mathrm{Cl}:-0.54$ to -0.05$), P=0.0 \mathrm{I}$ & Herth et $\mathrm{a}^{40}$ \\
\hline \multirow[t]{3}{*}{ DLCO } & One-way valves & 178 & $0.3 \mathrm{I} \mathrm{mL} / \mathrm{min} / \mathrm{mmHg}$ ( $95 \% \mathrm{Cl}:-0.58$ to I.20), $P=0.49$ & Wan et al, ${ }^{39}$ Sterman et al, ${ }^{38}$ Ninane et $a^{33}$ \\
\hline & BioLVR & 39 & $0.90 \mathrm{~mL} / \mathrm{min} / \mathrm{mmHg}$ (95\% Cl: 0.26 to I.54), $P \leq 0.0 \mathrm{I}$ & Herth et $\mathrm{al}^{19}{ }^{19} \mathrm{Kramer}$ et $\mathrm{a}^{31}$ \\
\hline & BTVA & 37 & $0.46 \mathrm{~mL} / \mathrm{min} / \mathrm{mmHg}$ (95\% Cl: -0.1 I to I.03), $P=0.1$ I & Herth et $\mathrm{a}^{40}$ \\
\hline \multirow[t]{7}{*}{$6 \mathrm{MWD}$} & One-way valves & 610 & $23.27 \mathrm{~m}(95 \% \mathrm{Cl}: 9.06$ to 37.48$), P=0.00 \mathrm{I}$ & Wan et al, ${ }^{39}$ Sterman et al,,$^{38}$ Sciurba et al,,$^{35}$ \\
\hline & & & & Chung et al, ${ }^{26}$ Santini et al, ${ }^{34}$ Herth et al,, 30 \\
\hline & & & & Herth et $\mathrm{al}^{29}{ }^{29}$ Ninane et $\mathrm{a}^{33}$ \\
\hline & BioLVR & 72 & $23.98 \mathrm{~m}$ (95\% Cl: $\mid 2.08$ to 35.88$), P \leq 0.0$ I & Criner et $\mathrm{al}^{27}$ Magnussen et $\mathrm{a}^{32}$ \\
\hline & LVRC & 16 & $84.4 \mathrm{~m}(95 \% \mathrm{Cl}: 48.43$ to $\mathrm{I} 20.36), P \leq 0.00 \mathrm{I}$ & Slebos et $\mathrm{al}^{37}$ \\
\hline & Airway bypass stents & 244 & $-20.19 \mathrm{~m}(95 \% \mathrm{Cl}: 32.98$ to $-7.4 \mathrm{I}), P=0.002$ & Cardoso et al, ${ }^{25}$ Shah et a ${ }^{36}$ \\
\hline & BTVA & 44 & I $6.24 \mathrm{~m}(95 \% \mathrm{Cl}:-1.92$ to $34.4 \mathrm{I}), P=0.08$ & Herth et $\mathrm{a}^{40}$ \\
\hline \multirow[t]{6}{*}{ SGRQ } & One-way valves & 479 & -13.53 points $(-24.38$ to -2.23$), P=0.01$ & Sterman et al, ${ }^{38}$ Sciurba et al, ${ }^{35}$ Chung et al, ${ }^{26}$ \\
\hline & & & & Santini et $\mathrm{al}^{34}{ }^{34}$ Herth et $\mathrm{al},{ }^{30}$ Herth et $\mathrm{al}^{29}$ \\
\hline & BioLVR & 72 & -8.88 points $(95 \% \mathrm{Cl}:-12.12$ to -5.64$), P \leq 0.00 \mathrm{I}$ & Criner et $\mathrm{al}^{27}$ Magnussen et $\mathrm{a}^{32}$ \\
\hline & LVRC & 27 & -10.79 points $(95 \% \mathrm{Cl}:-17.66$ to -3.92$), P \leq 0.0 \mathrm{I}$ & Herth et al, ${ }^{28}$ Slebos et al ${ }^{37}$ \\
\hline & Airway bypass stents & 244 & -1.02 points ( $95 \% \mathrm{Cl}:-2.89$ to 0.84$), P=0.28$ & Cardoso et al, ${ }^{25}$ Shah et al ${ }^{36}$ \\
\hline & BTVA & 44 & $-\mid 0.82$ points $(95 \% \mathrm{Cl}:-\mid 4.95$ to -6.70$), P \leq 0.00 \mid$ & Herth et $\mathrm{al}^{40}$ \\
\hline
\end{tabular}

Note: BioLVR indicates studies using sealants/hydrogels.

Abbreviations: 6 MWD, 6-minute walk distance; BTVA, bronchial thermal vapor ablation; Cl, confidence interval; DLCO, diffusion capacity of carbon monoxide; FEV , forced expiratory volume in the first second; FVC, forced vital capacity; LVRC, lung volume reduction coil; m, meters; N, total number of study participants; RV, residual volume; SGRQ, St George's Respiratory Questionnaire; TLC, total lung capacity.

Table 3 Post hoc analysis of studies with duration 6-12 months

\begin{tabular}{|c|c|c|c|c|}
\hline Outcomes & Subgroup & $\mathbf{N}$ & Mean difference & Studies \\
\hline \multirow[t]{2}{*}{$\mathrm{FEV}_{1}$} & One-way valves & 282 & $0.34 \mathrm{~L}(95 \% \mathrm{Cl}:-0.09$ to 0.79$), P=0.12$ & $\begin{array}{l}\text { Sterman et al }{ }^{38} \text { Sciurba et al, }{ }^{35} \\
\text { Santini et a }{ }^{34}\end{array}$ \\
\hline & BioLVR & 18 & $0.27 \mathrm{~L}$ (95\% Cl: 0.08 to 0.47$), P \leq 0.0 \mathrm{I}$ & Kramer et $\mathrm{a}^{3 !}$ \\
\hline \multirow[t]{2}{*}{6 MWD } & One-way valves & 393 & $26.67 \mathrm{~m} \mathrm{(95 \%} \mathrm{Cl:} 2.7 \mathrm{I}$ to 50.62$), P=0.02$ & $\begin{array}{l}\text { Herth et al, }{ }^{29} \text { Sterman et al, }{ }^{38} \\
\text { Sciurba et } \mathrm{al}^{35} \text { Santini et }\left.\mathrm{a}\right|^{34}\end{array}$ \\
\hline & BioLVR & 62 & I $6.97 \mathrm{~m}$ (95\% Cl: 3.20 to 30.74$), P=0.0$ I & Criner et $\mathrm{al}^{27}$ Kramer et $\mathrm{al}^{31}$ \\
\hline \multirow[t]{3}{*}{ SGRQ } & One-way valves & 393 & -16.78 points $(95 \% \mathrm{Cl}:-33.36$ to -0.20$), P=0.04$ & $\begin{array}{l}\text { Herth et al, }{ }^{29} \text { Sterman et a }{ }^{38} \\
\text { Sciurba et al, }{ }^{35} \text { Santini et al }{ }^{34}\end{array}$ \\
\hline & BioLVR & 62 & -1.02 points ( $95 \% \mathrm{Cl}:-2.89$ to 0.84$), P=0.28$ & Criner et al, ${ }^{27}$ Kramer et $\mathrm{al}^{31}$ \\
\hline & LVRC & 16 & -14.90 points ( $95 \% \mathrm{Cl}:-20.82$ to -8.97$), P \leq 0.00 \mathrm{I}$ & Slebos et $\mathrm{al}^{37}$ \\
\hline
\end{tabular}

Note: BioLVR indicates studies using sealants/hydrogels.

Abbreviations: 6 MWD, 6-minute walk distance; Cl, confidence interval; FEV , forced expiratory volume in the first second; LVRC, lung volume reduction coil; m, meters; N, total number of study participants; SGRQ, St George's Respiratory Questionnaire. 
in line were the proximal obstructing devices. ${ }^{42,43}$ However, because of their failure in producing effective LVR and the high incidence of procedural pneumothoraces, these devices soon fell out of favor. It was thought that flow from the extensive collateral ventilation (CV) pathways between and within the emphysematous lobes paradoxically led to hyperinflation distal to the occlusion. The one-way valves, because of their design, are less likely to be associated with the problem of "paradoxical hyperinflation". However, as was the case with one-way obstructing devices, certain factors such as $\mathrm{CV}$ and fissure integrity have a bearing on the long-term success of procedures with one-way valves. ${ }^{30,35}$ In the post hoc analyses of both the US and European Endobronchial Valve for Emphysema Palliation Trial (VENT) studies, factors such as fissure integrity on computed tomography lung scans and lobar occlusion were associated with significant LVR, and patients who exhibited these signs on computed tomography had significantly improved clinical outcomes. ${ }^{30}$ Most importantly, these results were sustained at 12 months post-procedure. Recently, Herth et al validated the use of a method to assess $\mathrm{CV}$ for predicting efficacy of one-way valves. ${ }^{29}$ Their results showed an accuracy of $75 \%$. It is likely that current ongoing research trials with one-way valves using this approach would show better outcomes compared to the earlier studies. In contrast to the one-way valves, the effect of BioLVR for LVR is not dependent on interlobar fissure integrity. ${ }^{32}$ The effects seem dose dependent, with the best effect produced by high-dose $(20 \mathrm{~mL} / \mathrm{sub}$-segment $)$ versus low-dose $\left(10 \mathrm{~mL} / \mathrm{sub}\right.$-segment) sealant. ${ }^{27}$ Aside from some shortterm complications, including treatment-related pneumonia (Figure S10) and COPD exacerbations (Figure S8), overall, as noted above, this method has been found to be very safe with no procedural mortality reported in studies. ${ }^{19,27,31}$ This is in contrast with the frequent procedure-related complications observed with one-way valves, such as pneumonia distal to valve implantation, valve- or procedure-related pneumothorax, and valve migration, as shown in Figures S5-S7.

Our meta-analysis has several strengths. It incorporated a total of 998 study participants from 17 different studies. We separately analyzed studies that followed participants for a minimum of 6 months to a maximum of 12 months. Study participants belonged to different countries and continents. This allows for some degree of generalizability of our findings. No evidence of publication bias was observed by statistical tests in our primary outcomes.

Our meta-analysis has several limitations. First, moderateto-high heterogeneity was observed in most of the analyses.
This could be because of the differences in the baseline characteristics of the study participants, procedural techniques, assessment of outcomes, and the geographic locations in which the studies were conducted. However, in order to account for the between-study variance, we used random effects model to report our results. Second, excluding the subgroup of one-way valves, most of the other subgroups did not have a sufficient number of studies, hence assessment of publication bias in these subgroups was not possible. Nevertheless, we believe that our search for studies was thorough and extensive. Third, most of the studies included in our meta-analysis were single-arm prospective trials and not RCTs and a few were pilot studies, which, as standalone studies, cannot be considered powered enough to draw strong conclusions from.

Despite these limitations, we believe our findings are significant, as this meta-analysis provides some form of comparability between the different methods of BLVR. We believe that future studies can benefit from the estimates of effect sizes provided in our meta-analysis.

\section{Conclusion}

These preliminary findings show that, excluding airway bypass stents, most of the methods of BLVR show efficacy in improving lung functions and exercise capacity. Moreover, these methods could likely be noninferior, if not equivalent, to LVRS. However, it is likely that, in clinical practice, the efficacy observed for most BLVR methods would be tempered with considerations of the technical peculiarities of each procedure (such as the absence or presence of $\mathrm{CV}$ in the case of one-way valves) and their associated complications. LVRS may still be considered first-line for patients with predominantly upper lobe emphysema and poor exercise capacity, and only a select number of patients could be considered for BLVR. This is because, firstly, there is no trial that directly compares LVRS and BLVR and, secondly, none of the bronchoscopic methods are approved by the US Food and Drug Administration. Given the preliminary nature of our findings, we believe that more trials are needed that are designed with a comparative effectiveness research model, involve a larger number of participants, with a much longer duration of follow-up, and with different markers of improvement than the ones traditionally used in earlier studies.

\section{Disclosure}

IHI and FRM report no potential conflicts of interest with any companies/organizations whose products or services may be 
discussed in this article. AIM was/is an investigator on the Spiration pivotal study (co-principal investigator), Aeris trial (principal investigator), EASE trial (principal investigator), and PneumRx trial (principal investigator). None of the authors report any funding source for this work.

\section{References}

1. Copd (chronic obstructive pulmonary disease) [webpage on the Internet]. National Heart, Lung, and Blood Institute; 2012. Available from: https://www.nhlbi.nih.gov/about/factbook/chapter4.htm. Accessed September 24, 2013.

2. 2007 nhlbi morbidity and mortality chart book. [webpage on the Internet]. Available from: http://www.nhlbi.nih.gov/resources/docs/07-chtbk. pdf. Accessed September 24, 2013.

3. De Giacomo T, Rendina EA, Venuta F, et al. Bullectomy is comparable to lung volume reduction in patients with end-stage emphysema. Eur $J$ Cardiothorac Surg. 2002;22:357-362.

4. Cassivi SD, Meyers BF, Battafarano RJ, et al. Thirteen-year experience in lung transplantation for emphysema. Ann Thorac Surg. 2002;74:1663-1669; discussion 1669-1670.

5. Fishman A, Martinez F, Naunheim K, et al; National Emphysema Treatment Trial Research Group. A randomized trial comparing lungvolume-reduction surgery with medical therapy for severe emphysema. N Engl J Med. 2003;348:2059-2073.

6. Naunheim KS, Wood DE, Mohsenifar Z, et al; National Emphysema Treatment Trial Research Group. Long-term follow-up of patients receiving lung-volume-reduction surgery versus medical therapy for severe emphysema by the national emphysema treatment trial research group. Ann Thorac Surg. 2006;82:431-443.

7. Naunheim KS, Wood DE, Krasna MJ, et al; National Emphysema Treatment Trial Research Group. Predictors of operative mortality and cardiopulmonary morbidity in the national emphysema treatment trial. J Thorac Cardiovasc Surg. 2006;131:43-53.

8. Ramsey SD, Berry K, Etzioni R, Kaplan RM, Sullivan SD, Wood DE; National Emphysema Treatment Trial Research Group. Cost effectiveness of lung-volume-reduction surgery for patients with severe emphysema. N Engl J Med. 2003;348:2092-2102.

9. Hopkinson NS, Toma TP, Hansell DM, et al. Effect of bronchoscopic lung volume reduction on dynamic hyperinflation and exercise in emphysema. Am J Respir Crit Care Med. 2005;171:453-460.

10. Snell GI, Holsworth L, Borrill ZL, et al. The potential for bronchoscopic lung volume reduction using bronchial prostheses: a pilot study. Chest. 2003; 124:1073-1080.

11. Toma TP, Hopkinson NS, Hillier J, et al. Bronchoscopic volume reduction with valve implants in patients with severe emphysema. Lancet. 2003;361:931-933.

12. Venuta F, Anile M, Diso D, et al. Long-term follow-up after bronchoscopic lung volume reduction in patients with emphysema. Eur Respir J. 2012;39:1084-1089.

13. Venuta F, de Giacomo T, Rendina EA, et al. Bronchoscopic lung-volume reduction with one-way valves in patients with heterogenous emphysema. Ann Thorac Surg. 2005;79:411-416; discussion 416-417.

14. Wood DE, McKenna RJ Jr, Yusen RD, et al. A multicenter trial of an intrabronchial valve for treatment of severe emphysema. $J$ Thorac Cardiovasc Surg. 2007;133:65-73.

15. Yim AP, Hwong TM, Lee TW, et al. Early results of endoscopic lung volume reduction for emphysema. JThorac Cardiovasc Surg. 2004;127: 1564-1573.

16. Refaely Y, Dransfield M, Kramer MR, et al. Biologic lung volume reduction therapy for advanced homogeneous emphysema. Eur Respir J. 2010;36:20-27.

17. Gompelmann D, Heussel CP, Eberhardt R, et al. Efficacy of bronchoscopic thermal vapor ablation and lobar fissure completeness in patients with heterogeneous emphysema. Respiration. 2012;83:400-406.
18. Snell GI, Hopkins P, Westall G, Holsworth L, Carle A, Williams TJ. A feasibility and safety study of bronchoscopic thermal vapor ablation: a novel emphysema therapy. Ann Thorac Surg. 2009;88:1993-1998.

19. Herth FJ, Gompelmann D, Stanzel F, et al. Treatment of advanced emphysema with emphysematous lung sealant $\left(\right.$ AeriSeal $\left.^{\circledR}\right)$. Respiration. 2011;82:36-45.

20. Sutton AJ, Abrams KR, Jones DR, Sheldon TA, Song F. Methods for Meta-analysis in Medical Research: Wiley Series in Probability and Statistics. New York, NY: John Wiley and Sons Inc.; 2000.

21. Huedo-Medina TB, Sánchez-Meca J, Marín-Martínez F, Botella J. Assessing heterogeneity in meta-analysis: Q statistic or I2 index? Psychol Methods. 2006;11:193-206.

22. Sankey S WL, Fine M, Kapoor W. An assessment of the use of the continuity correction for sparse data in meta-analysis. Commun StatSimul C. 1996;25:1031-1056.

23. Sterne JA, Egger M, Smith GD. Systematic reviews in health care: investigating and dealing with publication and other biases in meta-analysis. BMJ. 2001;323:101-105.

24. Begg CB, Mazumdar M. Operating characteristics of a rank correlation test for publication bias. Biometrics. 1994;50:1088-1101.

25. Cardoso PF, Snell GI, Hopkins P, et al. Clinical application of airway bypass with paclitaxel-eluting stents: early results. JThorac Cardiovasc Surg. 2007;134:974-981.

26. Chung SC, Peters MJ, Chen S, Emmett L, Ing AJ. Effect of unilateral endobronchial valve insertion on pulmonary ventilation and perfusion: a pilot study. Respirology. 2010;15:1079-1083.

27. Criner GJ, Pinto-Plata V, Strange C, et al. Biologic lung volume reduction in advanced upper lobe emphysema: phase 2 results. Am J Respir Crit Care Med. 2009;179:791-798.

28. Herth FJ, Eberhard R, Gompelmann D, Slebos DJ, Ernst A. Bronchoscopic lung volume reduction with a dedicated coil: a clinical pilot study. Ther Adv Respir Dis. 2010;4:225-231.

29. Herth FJ, Eberhardt R, Gompelmann D, et al. Radiological and clinical outcomes of using Chartis ${ }^{\mathrm{TM}}$ to plan endobronchial valve treatment. Eur Respir J. 2013;41:302-308.

30. Herth FJ, Noppen M, Valipour A, et al; International VENT Study Group. Efficacy predictors of lung volume reduction with Zephyr valves in a European cohort. Eur Respir J. 2012;39:1334-1342.

31. Kramer MR, Refaely Y, Maimon N, Rosengarten D, Fruchter O. Bilateral endoscopic sealant lung volume reduction therapy for advanced emphysema. Chest. 2012;142:1111-1117.

32. Magnussen H, Kramer MR, Kirsten AM, et al. Effect of fissure integrity on lung volume reduction using a polymer sealant in advanced emphysema. Thorax. 2012;67:302-308.

33. Ninane V, Geltner C, Bezzi M, et al. Multicentre European study for the treatment of advanced emphysema with bronchial valves. Eur Respir J. 2012;39:1319-1325.

34. Santini M, Fiorelli A, Vicidomini G, Di Crescenzo VG, Messina G, Laperuta P. Endobronchial treatment of giant emphysematous bullae with one-way valves: a new approach for surgically unfit patients. Eur J Cardiothorac Surg. 2011;40:1425-1431.

35. Sciurba FC, Ernst A, Herth FJ, et al; VENT Study Group. A randomized study of endobronchial valves for advanced emphysema. N Engl J Med. 2010;363:1233-1244.

36. Shah PL, Slebos DJ, Cardoso PF, et al; EASE trial study group. Bronchoscopic lung-volume reduction with Exhale airway stents for emphysema (EASE trial): randomised, sham-controlled, multicentre trial. Lancet. 2011;378:997-1005.

37. Slebos DJ, Klooster K, Ernst A, Herth FJ, Kerstjens HA. Bronchoscopic lung volume reduction coil treatment of patients with severe heterogeneous emphysema. Chest. 2012;142:574-582.

38. Sterman DH, Mehta AC, Wood DE, et al; IBV Valve US Pilot Trial Research Team. A multicenter pilot study of a bronchial valve for the treatment of severe emphysema. Respiration. 2010;79:222-233.

39. Wan IY, Toma TP, Geddes DM, et al. Bronchoscopic lung volume reduction for end-stage emphysema: report on the first 98 patients. Chest. 2006;129:518-526. 
40. Herth FJ, Ernst A, Baker KM, et al. Characterization of outcomes 1 year after endoscopic thermal vapor ablation for patients with heterogeneous emphysema. Int J Chron Obstruct Pulmon Dis. 2012;7:397-405.

41. Criner GJ, Sternberg AL. National Emphysema Treatment Trial: the major outcomes of lung volume reduction surgery in severe emphysema. Proc Am Thorac Soc. 2008;5:393-405.
42. Sabanathan S, Richardson J, Pieri-Davies S. Bronchoscopic lung volume reduction. J Cardiovasc Surg (Torino). 2003;44:101-108.

43. Watanabe S, Shimokawa S, Yotsumoto G, Sakasegawa K. The use of a Dumon stent for the treatment of a bronchopleural fistula. Ann Thorac Surg. 2001;72:276-278.

International Journal of COPD

\section{Publish your work in this journal}

The International Journal of COPD is an international, peer-reviewed journal of therapeutics and pharmacology focusing on concise rapid reporting of clinical studies and reviews in COPD. Special focus is given to the pathophysiological processes underlying the disease, intervention programs, patient focused education, and self management protocols.

\section{Dovepress}

This journal is indexed on PubMed Central, MedLine and CAS. The manuscript management system is completely online and includes a very quick and fair peer-review system, which is all easy to use. Visit $\mathrm{http}: / /$ www.dovepress.com/testimonials.php to read real quotes from published authors.

Submit your manuscript here: http://www.dovepress.com/international-journal-of-copd-journal 